\title{
SOCIAL AND HEALTH FACTORS ASSOCIATED WITH CHILDREN'S IMMUNIZATION STATUS IN THE LOCAL GOVERNMENT OF DJOUGOU IN BENIN
} IN 2013

\author{
Noudamadjo $\mathrm{A}^{{ }^{*}}$, Adédémy JD ${ }^{1}$, Agossou J ${ }^{1}$, Aniwanou $\mathrm{B}^{2}$, Salifou $\mathrm{S}^{2}$. \\ ${ }^{1}$ Department of Mother and Child, Faculty of Medicine, University of Parakou \\ ${ }^{2}$ Health Zone Office of Djougou - Benin
}

\begin{abstract}
Introduction: In Benin, in recent years, many measles' epidemics had been reported in some local governments, including the municipality of Djougou.

Objectives: This study aimed to assess children's immunization status and identify associated social and health factors.

Methods: This research work was a cross-sectional, descriptive and analytical study. It had been conducted from 29 to 31 August, 2013 and involved 410 children aged 12 to 23 months and their mothers/minders randomly selected through clustering technique in 30 villages of the Local government of Djougou.

Results: Coverages with BCG, DTP1 - Hep1 - Hib1, DTP2 - Hep2 - Hib2, DTP3 - Hep3 - Hib3 and Measles vaccines were respectively $96.30 \%, 92.90 \%, 89 \%, 84.60 \%$ and $72.00 \%$. Concerning immunization status, $29.02 \%$ of children were not fully vaccinated. Among the factors analyzed, 6 were associated with immunization status. Conclusion: This research work has pointed out that about one out of three selected children was not completely vaccinated. These findings may explain the occurrence of measles epidemics observed in the Local government.
\end{abstract}

Keywords: Immunization status, social and health associated factors, Benin.

\section{INTRODUCTION}

In Benin, infant and child mortality decreased from 167 to 125 for 1000 live births from 1996 to 2006 [1]. To reduce that mortality, the WHO considers that immunization helps avoid each year 2.5 million deaths of children associated with diphtheria, tetanus, whooping cough or pertussis and measles $[2,3]$. In the first semester of 2013, two measles' epidemics were registered in the municipality of Djougou, respectively in 8th and 17 th epidemiological weeks $[4,5]$. Investigations conducted enabled to suspect, among other factors, non-vaccinated targets among a certain number of the cases reported. This study aims to determine immunization coverage by antigen in children and identify the social and health factors associated with the immunization status of the children in the local government of Djougou in 2013.

\section{SETTING AND METHODS}

\section{Study setting}

The study took place in the local government of Djougou located in the Djougou-Copargo-Ouaké health zone. Djougou is located at about 450 kilometers from Cotonou and it covers a surface

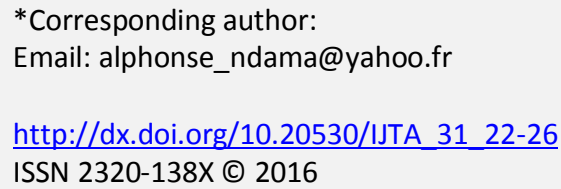

area of $3966 \mathrm{~km}^{2}$ with a total population estimated at 259,858 inhabitants in 2013. The local government has 13 health centers; each one has an immunization service. About $80 \%$ of the active population exert agricultural and animal husbandry activities. At social and cultural level, many ethnic group live together there. The main social and cultural group is the Yom-Lokpa group who represents $51.5 \%$ and Islam is the major religion practiced (72.3\%) [5]

\section{Type, population and period of study}

It is a cross-sectional, descriptive and analytical study which was carried out from August 29 to 31, 2013. Population study consisted of children aged 12 to 23 months in the study period. It also included their mothers/minders and immunization services officers of the local government. Sample size had been determined by means of Schwartz formula with $k=2$ clustering effect. Number of children per cluster was $392 / 30=13.06$ rounded to 14 and to $420(14 \times 30)$ according to WHO recommendation.

\section{Sampling technique}

It was a cluster sampling.

\section{Study variables}

The study dependent variable is immunization status, a binary variable which is Good" for completely vaccinated child, and "Poor" for incompletely vaccinated child. The independent variables were grouped into sociodemographic and 
Table I: Distribution of children's immunization status according to some social and health characteristics

\begin{tabular}{|c|c|c|c|c|c|}
\hline \multirow[b]{2}{*}{ Variable } & \multicolumn{5}{|c|}{ Incompletely vaccinated children } \\
\hline & Total (N) & Number & Percentage (\%) & P-value & $\mathrm{Khi}^{2}$ \\
\hline \multicolumn{6}{|c|}{ Mother's educational status } \\
\hline Enrolled in school & 174 & 32 & 18.39 & & \\
\hline Uneducatedl & 236 & 87 & 36.86 & 0.000004 & 16.59 \\
\hline \multicolumn{6}{|c|}{ Decision-making on child health } \\
\hline Mother & 234 & 73 & 31.20 & & \\
\hline Other relative & 176 & 46 & 26.14 & $<0.0000001$ & 37.66 \\
\hline \multicolumn{6}{|l|}{ Household size } \\
\hline Small (<4 children) & 99 & 37 & 37.37 & & \\
\hline Large & 311 & 82 & 26.37 & 0.03 & 4.42 \\
\hline \multicolumn{6}{|c|}{ Number of antenatal care (ANC) } \\
\hline No ANC & 21 & 18 & 85.71 & & \\
\hline 1 or more ANC & 389 & 101 & 25.96 & $<0.000000001$ & 31.69 \\
\hline \multicolumn{6}{|l|}{ Place of birth } \\
\hline Residence & 38 & 25 & 65.79 & & \\
\hline Health centre & 372 & 94 & 25.27 & 0.00000002 & 27.48 \\
\hline \multicolumn{6}{|c|}{ Family migrating from a rural area } \\
\hline Yes & 68 & 40 & 58.82 & & \\
\hline No & 342 & 79 & 23.10 & $<0.00000001$ & 34.14 \\
\hline
\end{tabular}

economic factors of the mother, child-related factors, sociocultural factors and factors related to geographical accessibility.

\section{Technique and tools for data collection}

The data collection techniques used were structured individual interview with mothers/minders of eligible children. As data collection tool, we used a questionnaire to be filled in by mothers/minders.

\section{Data processing and analysis}

Data were entered analyzed with Epi info software version 3.5.1. Frequency and association measures served to describe and analyze the data collected. Karl Pearson's chi-square $\left(X^{2}\right)$ uncorrected test and Fisher's exact test were used to identify an association between two variables. Threshold for statistical significance was set at $p=$ 0.05 . We admitted that there was statistically significant associations between two variables for any probability lower than $0.05(p<0.05)$.

\section{Ethical and professional considerations}

The informed consent and favorable opinion of target children's parents were obtained after explaining them the purpose of the survey, its implementation and its interest. The respondents were reassured concerning anonymity and confidentiality of collected informations. For this purpose, we used digital characters as identification marks for our survey questionnaires. We requested the authorization of political and administrative authorities and got it.

\section{RESULTS}

In total, 420 children aged 12 to 23 months, 420 mothers/minders participated to the study. No target of the sample refused to answer interviewers' questions. We excluded from the analysis the data of 10 children and of their mothers/minders (2.38\%) for non-compliance with inclusion age criterion and data inconsistency. Therefore, the analysis focused on 410 children and 410 mothers/minders.

\section{Sociodemographic characteristics of the children}

Girls represented $50.20 \%$ and boys $49.80 \%$, i.e. a sex-ratio of 0.99 . Rank 4 and above among the siblings were more represented (36.34\%) and elders (rank 1) represented $22.93 \%$ of the sample with extremes from 1 to 8 . Thirty-eight out of 410 children, i.e. $9.27 \%$ were born at home against 372 out of 410 i.e. $90.73 \%$ in a health center.

\section{Characteristics of children's mothers or minders}

Mean age was 27.79 years \pm 5.75 years. The most represented age group was the one from 21 to 35 years (78.29). They consisted of $27.07 \%$ of resellers and $23.66 \%$ who do not exert any professional activity. Those who perform an income generating activity represent $76.34 \%$. The 
majority practiced the Islamic religion (80.73\%) and lived in rural areas (70.49\%). Mothers/minders had an income comprised between 31,500 F CFA (63 US Dollars) and 100,000 F CFA (200 US Dollars) per month in $51.95 \%$ of the cases. In $43.42 \%$ of the cases, they earned less than 31,500 F CFA (Guaranteed Minimum Salary in Benin) and 4.63\% had more than 100,000 F CFA per month. As regards educational status, $60.00 \%$ of mothers had not received any education against $40.00 \%$ who attended school, including $25.12 \%$ with primary school level, $14.63 \%$ with secondary school and $0.25 \%$ with university level. In $5.12 \%$ of the cases, mothers had never benefitted from antenatal consultation while bearing the pregnancy of the child interviewed, but the majority (74.88\%) had benefitted from at least three consultations; the remaining proportion (20.00\%) benefited from 1 to 2 antenatal consultation. The average number of persons by household was $5.72 \pm 3.36$. In $75.85 \%$ of the cases, these were large households (more than 3 children). The study demonstrated that $65.61 \%$ of mothers socialized into village while $34.39 \%$ into town. More than half of those mothers (57.07\%) have decision-making power on child health. Cultural prohibitions and taboos related to vaccination were notified by mothers in $4.15 \%$ of the cases against $95.85 \%$ who claimed that this barrier to vaccination did not exist in their living environment.

\section{Immunization coverages}

According to vaccination cards and mothers' statements, coverages with tuberculosis vaccine (BCG), vaccines against diphtheria tetanus, pertussis, haemophilus influenzae $b$, and viral hepatitis B 1st, $2^{\text {nd }}$ and 3rd doses (DTP1-Hep1Hib1, DTP2-Hep2-Hib2, DTP3-Hep3-Hib3) and eventually against measles/yellow fever (MV/YFV) were respectively $96.30 \% ; 92.90 \% ; 89 \% ; 84.60 \%$ and $72 \%$. According to the vaccination card only, those coverages were respectively $97.90 \%$; 96.40\%; 92.50\%; $87.90 \%$ and $77.20 \%$ for BCG, DTP1-Hep1-Hib1, DTP2-Hep2-Hib2, DTP3-Hep3Hib3 and MV/YFV respectively. According to statements and vaccination cards, $3.41 \%$ did not receive any antigen against $2.10 \%$ according to vaccination card only. Out of the 410 children, 291 were fully vaccinated (70.98\%) against 119 incompletely vaccinated children (29.02\%).

\section{Factors associated with immunization status}

The analysis pointed out that mothers/minders' educational status, decision-making power, size of household from which the child was born, number of antenatal care (ANC), place of birth, and ruralurban migration were factors significantly associated with immunization status as indicated in Table I.

Besides, many other factors investigated were not significantly associated with immunization status. These are mother's age $(p=0.93)$, her marital status $(P=0.44)$, occupation $(p=0.25)$, religion $(p=0.42)$, ethnic group $(p=0.05)$, monthly income $(P=0.50)$ and her residence in town or not $(p=0.61)$, child sex $(p=0.13)$ and rank among the siblings $(p=0.06)$, and immunization side-effects $(p=0.05)$.

\section{DISCUSSION}

The cluster sampling method validated in several studies on immunization coverage was used for the selection of villages/areas visited. As well, the questionnaire used derived from standardized models $[1,6,7]$. Nevertheless, this study has some limits related to information gathering in children with no documents. However, all the preventive measures taken certainly helped to reduce possible information biases and contributing to validity of results.

The immunization coverages encountered in this research work, compared to 2013 national standards which were $98.00 \%$ for BCG, $96.00 \%$ for DTP3-Hep3-Hib3 and $92.00 \%$ for measles vaccine (MV) and yellow fever vaccine (YFV), indicate a gradual decline in BCG coverages with MV/YFV. These shortfalls may be due to lack and obsolescence of rolling stock, inadequacy and lack of motivation of staff, poor reception and decline in sensitization on immunizations. These results are similar to those found out by EPI review in 2008 in Benin [6], and those published by Faye et al in Senegal in 2010 [8]. But they are different from those of Bouvier et al in Switzerland in 1994 [9], and of 3rd Population and Health Survey (EDS III) carried out in Benin in 2006 [1]. The differences observed with Bouvier et al may be due to the fact that study population is European and its health culture would seem to be more receptive to adherence to vaccination.

The proportion of incompletely vaccinated children was $29.02 \%$. The result is close to $30.40 \%$ and $32.00 \%$ respectively found by Makoutodé et al in 2006 in Benin [7] and by EPI review in Benin in 2008 [6]. In 2010, Faye et al [8] had found in Senegal $32.60 \%$. But it is different from the one of Benin $3^{\text {rd }}$ Population and Health Survey (PEDS III) in 2006 [1] which found out that $53.00 \%$ of the children had not been completely vaccinated.

The percentage of incompletely vaccinated children significantly declined according to educational status. This may be due to the fact that 
uneducated mothers were poorly informed on immunization compared to those educated. Makoutodé et al had made the same observation in Benin [7].

In this study, we identified a statistically significant association between immunization status and decision-making concerning child health. Indeed, the rate of incompletely vaccinated children (31.20\%) increased more significantly in children of mothers/minders with decision power than in children whose decision power was held by fathers, grand-parents or other parents (26.14\%). This proves that mothers' decision power is not sufficient to improve child immunization status. Other conditions are required, such as education which was already identified as a factor associated with immunization status. Sermé made the same remark in Burkina-Faso in 2011 [10]. But Makoutodé et al [7] had not identified an association between immunization status and decision-making concerning child health.

Although the rate of incompletely vaccinated children was higher in low-income households than in high-income households, the difference between both rates was not statistically significant. Bossali et al had made the same remark [11]. However, in Turkey, Ozkaya et al [12] had found a different result. The absence of association between monthly income and immunization status identified in this research work may be due to the fact that costs incurred in performing immunization were not high.

As far as area of residence, is concerned, the percentage of incompletely vaccinated children in urban areas was practically the same as in rural area. The difference between both percentages was not statistically significant. The results of Belachew et al in Ethiopia in 2012 [13] agree with this remark. But Sermé [10] identified an association between immunization status and area of residence. The absence of association noted may be related to immunization care provision in urban and rural areas which is hardly the same in the Local government thanks to implementation of advanced vaccination strategies. A significant relationship was identified between immunization status and size of the household from which the child was born. This may be due to the positive experience acquired by mothers with more than four children. Makoutodé et al had made the same observation in 2006 in Benin [7]

This study identified a significant association between place of birth and immunization status. Actually, children born at home are less likely to be fully vaccinated than their counterparts delivered in a health center. These findings enable to think that the resolution of home delivery problem will enable to impact positively on children's immunization status. This result agrees with the one found by Sia et al in Burkina-Faso in 2007 [14]. But, Makoutodé et al [7] did not identify an association between place of birth and immunization status.

The percentage of incompletely vaccinated children was significantly higher in children whose mothers did not benefit from any antenatal care. In Burkina-Faso, Sia et al [14] had made the same remarks, like Belachew et al in Ethiopia in 2011[13]. As a matter of fact, children whose mothers kept in touch with health services from the beginning of pregnancy are more likely to be vaccinated or completely vaccinated, than their counterparts from mothers who do not attend a health center on a regular basis. Therefore, a regular attendance by those women of information sessions preceding each antenatal care, focused among others on children's vaccination, may have generated the difference noted.

This research work has also demonstrated that the percentage of incompletely vaccinated children significantly increased through migration movement of children. This may be due to different migration pitfalls such as loss of vaccination cards, disorientation, loss of usual channels of immunization and economic instability. Therefore, it is necessary to develop other immunization strategies to reach those specific targets which are vulnerable.

\section{CONCLUSION}

The study conducted in the Local government of Djougou has pointed out that one out of three children was not completely vaccinated. Many factors related to social and health areas were identified as associated with immunization status. These are, among others, poor reception, missed opportunities for vaccination, absence of advices on vaccination, mothers' poor knowledge on EPI and immunization schedule. The percentage of incompletely vaccinated children identified in the study may well account for occurrence of measles epidemics in the local government and throughout the country. Therefore, it is necessary to develop sustainable strategies focused on factors identified in this research work so as to improve immunization coverages and keep them above national standards.

\section{ACKNOWLEDGMENTS}

We would like to extend our gratitude to the mothers of the children involved in this research 
work for their availability and cooperation. We would also like to thank the vaccination services officers of the local governments' health centers for their contribution to this work.

\section{Conflict of interest: None}

\section{REFERENCES}

1- Institut National de la Statistique et de l'Analyse Economique (INSAE) [Bénin] et Macro International. Enquête démographique et de santé 2006 : rapport de synthèse. USA : Calverton, Maryton ; Décembre 2007. P 8-10.

2- Organisation Mondiale de la Santé (Suisse). Statistiques sanitaires mondiales. Genève : OMS ; 2011. p2-13

3- Organisation Mondiale de la Santé (Suisse). La vaccination dans le monde : vision et stratégie. Genève : OMS ; 2010. p1-2.

4- Zone sanitaire Djougou (Bénin). Rapport investigation d'épidémie de rougeole dans la commune de Djougou. Djougou: DCO ; 2012. p511.

5- Zone sanitaire Djougou (Bénin). Rapport d'investigation du second épisode d'épidémie de rougeole dans la commune de Djougou. Djougou : DCO ; 2013. p10.

6- Ministère de la Santé (Bénin). Revue externe 2008 du PEV : Rapport final. Cotonou: MS; 2009. P4-159.

7- Makoutode M, Mohamed S, Paraïso NM, Guevart E, Akpaka Nago MR, Bessaoud K. Influence de certaines caractéristiques parentales sur la couverture vaccinale des nourrissons au Bénin. Med Trop $2009 ; 69$ : 267-71.
8- Faye A, Seck I, Dia A T. Facteurs d'abandon de la vaccination en milieu rural sénégalais. Médecine d'Afrique noire 2010; 57 (3): 137-41.

9- Bouvier P, Valdez E, Toscarti L, Restellini JP. Couverture vaccinale des enfants de 2 ans à Genève. Social and Preventive Medicine 1994; 39 (1) : p 56-62.

10- Sermé M. Déterminants communautaires de la fréquence élevée des abandons de la vaccination entre le BCG et le VAR chez les enfants de 0 à 11 mois dans la ville de Pouytenga (Burkina Faso). Mémoire: Epidémiologie: Burkina-Faso ; 2011. P51-86.

11- Bossali F, Paraïso M, Bokossa M, Fourn L. Etude des facteurs influençant la couverture vaccinale contre I'hépatite $B$ chez les enfants de 1 à 8 ans dans la zone sanitaire de Ouidah au Bénin en 2007. Med trop $2010 ; 70: 149-54$.

12- Ozkaya E, Cambaza N, Kolsuza LD, Aycanb N, Calis SB, Samancia N. Vaccination coverage and risk factors for incomplete vaccination in children with recurrent wheeze. Allergol Immunopathol 2011;39(4):222-7.

13- Belachew E, Wakgari D. Factors associated with complete immunization coverage in children aged 12-23 months in Ambo Woreda, Central Ethiopia. BMC Public Health 2012, 12: 566.

14- Sia D, Kobiané JF, Sondo BK, Fournier P. Les facteurs individuels et du milieu de vie associés à la vaccination complète des enfants en milieu rural au Burkina Faso: une approche multi-niveau. Cahier de santé 2007 ; 17 (4) :p202-6. 